\title{
Village Characteristics and Health of Rural Chinese Older Adults: Examining the CHARLS Pilot Study of a Rich and Poor Province
}

\author{
Authors: \\ Dale E. Yeatts, $\mathrm{PhD}^{\mathrm{a}}$ \\ Xiaomei Pei, $\mathrm{PhD}^{\mathrm{b}}$ \\ Cynthia M. Cready, $\mathrm{PhD}^{\mathrm{a}}$ \\ Yuying Shen, $\mathrm{PhD}^{\mathrm{c}}$ \\ Hao Luo, $\mathrm{PhD}^{\mathrm{b}}$ \\ Junxin Tan, M.A. ${ }^{\mathrm{b}}$
}

${ }^{a}$ University of North Texas, Department of Sociology, Box 311157, Denton, Texas. Please send all correspondence to: Yeatts@unt.edu; 940-565-2238.

${ }^{\mathrm{b}}$ Tsinghua University, Department of Sociology, Beijing, China.

${ }^{\mathrm{c}}$ Texas Tech University, Department of Sociology, Lubbock, Texas.

Acknowledgements: Collection of the data was supported by the U.S. National Institute on Aging, the China National Natural Science Foundation, and the World Bank, China. 


\begin{abstract}
Community (or village) characteristics have received growing attention as researchers have sought factors affecting health. This study examines the association between a variety of environmental, economic, and social village characteristics and health of Chinese older rural adults with health measured in terms of physical limitations. The Chinese Health and Retirement Longitudinal Survey (CHARLS) Pilot Study data were used. Older villagers from a low-income province (Gansu) and a relatively wealthy province (Zhejiang) were surveyed between July and September, 2008. The sample included 1,267 respondents in 73 villages age 45 and older. The relationship between a variety of village characteristics and physical limitations of older adults was examined using negative binomial regression (NBR) with standard errors adjusted to account for non-independence of respondents in a village. A comparison of means/percentages shows that Gansu and Zhejiang were significantly different on the dependent and most independent variables. The NBR models show that at the personal-level, decreased risk of physical limitations was associated with being male, less than 60 years old, married, higher in education, and higher in household expenditures (proxy for income). At the village-level, decreased risk of limitations was associated with a continuous supply of electricity, not using coal in the household, the existence of a sewage system, low cost of electricity, and village wealth. Decreased risk of physical limitations was also associated with various characteristics of China's New Cooperative Medical Scheme (NCMS), an insurance program for rural older adults. Policy implications for improved health of rural older adults include: (1) continued use of China's NCMS, (2) establishment of village sewage systems, (3) ending the use of coal in the home, and (4) increased educational opportunities focused on health.
\end{abstract}




\section{Introduction}

The characteristics of communities and villages have received a great deal of attention worldwide over the past 30 years. These include a focus on a variety of environmental, economic, and social characteristics that are believed to create and maintain good health. The purpose of this paper is to examine the general propositions that environmental, economic, and social characteristics of a village are associated with the health of rural Chinese older adults. Urban communities were excluded from the analyses in order to improve the interpretation of the data. Urban communities are very different from Chinese rural villages, such as by having more government financial supports, more developed community infrastructure, and more social supports (Zimmer, et al., 2007).

\section{Change in Rural and Urban China}

Chinese rural villages and urban communities have undergone tremendous change since 1949 when the Chinese communist party took control of the country. They experienced the “Great Leap Forward” initiated in 1958, the cultural revolution in the later half of the 1960's, and, in the 1980's they were introduced to a capitalist economic system that replaced many of the existing social programs such as national health care. In addition, they experienced the beginning of the "one-child" rule in the 1980's. Further, rural villages and urban communities have had very different experiences during these transitions (Bian \& Zhang, 2002). Today, Chinese villages are typically comprised of farmers, with some small businesses and often with some industry. Rural residents are more likely to be poor and less likely to have access to government related income and social programs than urban residents (Pei \& Xu, 2011). Modern Chinese cities are bustling with economic activity and receive a relatively large amount of 
financial support from the Chinese central government. Chinese villagers are often attracted to the city by its allure of potential riches and excitement. Meanwhile, this out-migration leaves many villages in a somewhat precarious position as their environmental infrastructure is under supported, and their income and social systems are threatened (Tilt, 2010).

These many changes have been particularly difficult for the Chinese rural and urban elderly (Chow \& Bai, 2011; Li \& Dorsten, 2011; Pei, 2008). In the past, the family was a multigenerational, extended one where the young deferred to and care for their elders. Family wealth was passed down from generation to generation and filial piety was strictly practiced (Zavoretti, 2006). However, today, recent economic and social changes have greatly diminished these traditional and social practices (Chen \& Meltzer, 2008; Wang, et al., 2011). The financial and social needs of the elderly are no longer being met by their children. Likewise, the central government no longer provides total support to the elderly. Subsequently, many of the Chinese elderly are left with fewer financial and social supports than in years past (Pei \& Xu, 2011; Giles $\& \mathrm{Mu}, 2007)$.

The Chinese central government has recognized problems that rural and urban older adults face and has been working to support them. For example, the central government has attempted to establish a financially solvent pension system for all elderly and a New Cooperative Medical Scheme designed to provide universal health coverage (Li \& Zhang, 2012; Lei \& Lin, 2009). The central government is continuing to search for ways to improve financial and social support for older adults. This study contributes to this effort by identifying environmental, economic, and social conditions associated with the health of older adults living in Chinese rural villages. 


\section{Environmental, Economic, and Social Conditions Affecting Health}

We propose that the environmental, economic, and social conditions of rural Chinese older villagers are associated with their health. The literature largely supports these propositions and is reviewed below.

\section{Environmental Conditions:}

A village's environment is typically described as all the physical characteristics associated with it and often includes village infrastructure. Typical environmental characteristics that received particular attention include air and water pollution (Wen \& Gu, 2011; Pervin, et al., 2008; Kan, et al., 2008; Brunekreef \& Holgate, 2002), erosion of soil (Tilt, 2010), generation of toxic materials and waste (Weichenthal, et al., 2011; Zhang, et al., 2010), and the use of pollutants such as coal and other fossil fuels (Chen, et al., 2011; Wong, et al., 2009). Infrastructure can include the existence and development of sewage, electrical, and road systems (Hunter, et al., 2011; Hart, 2006). Studies have shown that air and water pollution have negative effects on health. Similarly, a community's generation of toxic materials and waste and lack of sufficient energy for heating and cooling homes have been associated with poor health (Shaw, et al., 2002; Kruger, et al., 2007). Reported environmental health effects range from minor health concerns to communicable diseases to death (Martin \& Preston, 1994; Hunter, et al., 2011).

\section{Economic Conditions:}

A village's economic characteristics range from micro-scale factors focused on individuals living in the village to macro-scale factors that include the economy of the entire village, region, province, and nation (Mazmanian \& Kraft, 2009). Typical characteristics at the 
micro-level include the wealth of individuals and the effects of income disparities between them (Li \& Chi, 2011; Li \& Zhu, 2006; Chen \& Meltzer, 2008; Ji, 2013). At the macro-level, a great deal of attention has been focused on retirement and pension programs (Pei \& Xu, 2011; Pei, 2009). Retirement benefits available to older Chinese are most often provided by the Chinese government and are most prevalent among those living in urban areas (Pei \& Tang, 2010). The central government has been experimenting with ways of providing financial support or pension programs to rural older Chinese; however these initiatives are understandably limited given the large size of this population. Other macro-level, economic conditions include, for example, the production of goods and services occurring within the village, their transport and trade, and the disposal of used products and waste materials (Hart, 2006; Zeng, et al., 2010). The Chinese central government has made economic development a high priority. It has invested in infrastructure for industrial development, foreign trade, and the development of high-tech industries. However, in the past this investment has typically benefitted urban areas much more than rural (Tilt, 2010). A major criticism of economic development in China has been its lack of acknowledgement of potential negative effects on the health of local residents. As Li and Dorsten (2011) have noted: "Health care, particularly in remote and minority areas...receives very little, if any, attention in the blueprint for economic development" (p.54).

\section{Social Characteristics:}

Social factors at the micro and macro-levels have been found to be important to the health of a community's residents (Berkman, et al., 2000; Veenstra, et al., 2005; Hart, 2006). At the micro-level, families, neighbors, and friends work to create and maintain a supportive social environment (Pei \& Tang, 2010; Yip et al., 2007; Mohnen, et al., 2011; Ellen, et al., 2001; Hou 
\& Myles, 2005; Pynnonen, et al., 2012). For example, filial piety in China and similar norms and values in other cultures provide social and emotional support to older persons. At the village level, some villages have established "community centers" that offer social activities for older adults (Xu, et al., 2005). These social supports have become increasingly important with the changing dynamics of the Chinese family and its struggle to support the elderly. As Pei and Tang (2010) have noted: "As the ability of the family to provide care for their elderly members has been undermined by the shrinking of family size and tendency toward nuclear family type, families no longer possess the capacity to provide adequate care" (p.5).

At the macro-level, village, regional, provincial and central governments contribute to the current and future welfare of village residents (Ross \& Mirowsky, 2008). In particular, the Chinese central government has attempted to respond to the changing social systems in China by introducing new social support programs, particularly for the poor, disabled, and elderly (Ye, 2011; Gui, 2002; Xun, 2002). As noted above, one very expensive program is the New Cooperative Medical Scheme introduced by the Chinese central government as a means of providing medical insurance for the rural population in order to provide households with protection against the impoverishing impact of major illness (Li \& Zhang, 2012; Lei \& Lin, 2009; Yi, et al., 2009; Yip \& Hsiao, 2009). The NCMS is funded by a combination of household contributions and allocations by different levels of government. Household contributions are paid by older adults and vary depending on the contributions of the local village. In the case of poor provinces, the central government provides a fiscal transfer of a defined amount of money per beneficiary, on the condition that local governments provide matching funds. The schemes are administered by county governments, which are allowed to design and implement their own programs according to their specific needs with respect to deductibles, copayments, premiums, 
and coverage (State Council, 2002; Ministry of Health, 2003). The program was piloted in selected provinces in 2003 and was fully implemented in 2008 (Pei, 2011; Lei \& Lin, 2009).

\section{Methods}

Data Collection Design and Procedures

Data collected from the Chinese Health and Retirement Longitudinal Survey Pilot Study (CHARLS) were used to examine the relationship between the physical limitations of Chinese rural older adults and environmental, economic, and social conditions. The design and data collection procedures are described in detail in Zhao, et al. (2009) and Strauss, et al. (2011). A team of researchers from Peking University, the University of Southern California, and Oxford University developed the survey instruments and procedures.

Persons aged 45 years and older and their spouses were randomly selected from two Chinese provinces between July and September, 2008. While spouses of respondents were included in the pilot study, we limited our analyses to the person in each household who was initially randomly selected for the study. We also limited our analysis to respondents living in a village. Urban communities were excluded from the analysis. "Elderly" is typically thought to begin at age 60 or perhaps as young as 50 , therefore, we use the term "older adults" to describe the CHARLS respondents.

The sampling procedure used probability proportionate to size techniques. Sampling occurred at four stages with the primary sampling units being rural villages and urban communities. The number of households sampled from each unit ranged from 5-24. The two provinces surveyed included Gansu and Zhejiang. Gansu is the poorest and one of the most rural provinces located in the north central to western part of the country (Strauss, et al., 2011). 
Zhejiang is one of the wealthiest provinces, located on the central east coast of China, with a strong and relatively large private sector. The total sample size for all respondents living in a village was 1,267 and included 73 villages. Among these, one or more village-level characteristics were missing from nine villages containing 102 respondents. After removing these respondents and respondents with missing values on individual-level characteristics, 1,092 respondents in 64 villages (with a range of 7-24 and an average of 17 respondents in a village) were included in the regression analyses.

The questions and design of CHARLS are intended to mirror, in part, the Health and Retirement Survey developed and used in the United States, as well as similar health and retirement surveys developed and conducted in Australia, Great Britain, Europe and South Korea. Multiple survey instruments were used for each respondent and the subsequent data were organized into seven sections. Multiple visits were made to interview each respondent, to interview a local official of the village or community where the resident resided, and an interviewer's observations of each resident's surroundings were also recorded. Data were collected with respect to the respondent's health and well-being, family, work, income, retirement and pension, expenditures and assets, and health care insurance. Characteristics of the respondent's village or community were obtained from a local village official.

\section{Dependent and Independent Variables}

A "count" variable of physical limitations was created to represent the dependent variable, health. The variable "physical limitations" was chosen to represent health because it provided a valid measure of health while also being reported by most of the respondents (i.e., prevented a large number of missing cases). Respondents were asked if they had difficulty with 
five instrumental activities of daily living (IADLs) including household chores, preparing hot meals, shopping for groceries, managing money, and taking medications. They were also asked about difficulties with seven other functional activities such as, running and jogging about $1 \mathrm{~km}$; getting up from a chair after sitting for a long period; climbing several flights of stairs without resting; stooping, kneeling or crouching; reaching or extending arms above shoulder level; lifting or carrying a weight (such as a heavy bag of groceries); and picking up a small coin from a table. The original response set for each of the items included: 1="no, I don't have any difficulty;" 2="yes, I have difficulty;" and, 3="I cannot do it." Responses to each of the 12 items were recoded 0 for "no, I don't have any difficulty" and 1 for "yes, I have difficulty" or "I cannot do it." These responses were then summed to construct the dependent variable, number of IADL/functional limitations (also referred to as physical limitations), with a range of 0 , indicating no IADL/functional limitations, to 12 , indicating difficulty performing all 12 activities.

Independent variables included environmental, economic, and social variables. The three environmental variables were: (1) number of households using coal in the village, (2) existence of a sewage system in the village (coded 1 for "yes" and 0 for "no"), and (3) the dependability of electricity in the village. With regard to "number of households using coal in the village," a large percentage of villages had no households using coal. Thus, to better reflect the distribution of the variable in the overall sample and to assist with the substantive interpretation of the variable, we created a dichotomous variable where 0 was assigned to a respondent if no one in his/her village used coal in the household (49\% of respondents) and 1 was assigned to all respondents where at least one household in the village used coal (51\% of respondents). A similar adjustment was made for other variables found to have skewed distributions, including 
the dependability of electricity, where 59\% of respondents reported having electricity 365 days per year and were recoded 1 , with other respondents recoded 0 .

Three economic variables were included in the study. Following other studies of China and other developing countries, (logged) expenditures per household member in 2007 were used to measure the villager's household resources (a proxy for income) (Herrin, et al., 2013; Strauss, et al., 2010). Village-level variables were the average unit price for electricity and (logged) per capita income in 2007. We used a natural logarithm transformation of the expenditures and income variables for two reasons: (1) to capture the expectation that their effects on physical limitations are nonlinear (i.e., an increase in yuan from 200 to 400 has a stronger effect than an increase from 1000 to 1200) and (2) to correct for right-skew in the distributions.

Three of the social variables were (1) the number of village programs for older adults (ranging from 0 to 4 programs); (2) the existence of a health care organization in the village (coded 1 for "yes" and 0 for "no"); and (3) marital status (coded 1 for currently married or partnered because an overwhelming majority of respondents had this status, and coded 0 otherwise). Three additional social variables related to the central government's New Cooperative Medical Scheme: (4) year the NCMS started in the village; (5) how much the villager paid to participate; and (6) the percentage of villagers who participated. The NCMS start date in the village was recoded as ' 1 ' if the program had been operating 3 years or less in the village and ' 0 ' if it had been in operation for a longer period of time.

Control variables included the villager's age, sex, education, and Hukou status (place of birth). Previous work has demonstrated the importance of controlling for these variables in research to assess health (Orme \& Dooris, 2010; Beydoun \& Popkin, 2005). Each of these variables was dummy-coded. For instance, age was recoded ' 1 ' for respondents aged 60 or older, 
i.e., born before 1949, when the People's Republic of China was founded, and recoded ' 0 ' for those aged between 45 and 59 . Sex was coded ' 1 ' for males and ' 0 ' for females. Education was coded ' 1 ' for no formal education and ' 0 ' for other respondents because nearly one-half of respondents had no formal education. All Chinese residents have a Hukou status (HS), which is typically their village or city of birth. But, HS can be transferred to a different village, to a city, or from a city to a village with government approval. Urban HS has historically been associated with greater privilege within Chinese society (Chan \& Buckingham, 2008). Thus, the variable is coded as ' 0 ' for urban HS (rural villagers who have an urban HS) and ' 1 ' for rural HS.

In sum, data measuring the independent variables were either at the individual or village levels. Individual data were collected from the respondents and included the dependent variable; (number of physical limitations), all four control variables (sex, age, education, and HS), none of the environmental variables, one of the economic variables (expenditures per household member), and one of the social variables (marital status). The data used to describe the village level variables came from a survey of a village leader who was asked to provide information about the respondent's village. These latter variables included the three environmental variables (the number of days per year the village has electricity, the number of households in the village using coal, and whether a sewage system exists in the village), two economic variables (the village's per capita income and the average unit price for electricity in the village), two social variables (whether a health organization was located in the village and the number of programs for older adults), and the three variables measuring characteristics of the NCMS within the village. Unfortunately, it is unclear how accurate or unbiased the data are that were collected from village leaders. Therefore, these data must be considered cautiously. This is discussed further in the limitations section. 
Analyses

The data were analyzed using negative binomial regression models. While count variables, such as our dependent variable, are sometimes analyzed using Poisson regression models (Hoffman, 2004) the Poisson regression assumes that the mean of the dependent variable equals the variance (referred to as equidispersion). This is not the case for our dependent variable. That is, when examining each province the variance of the number of IADL/functional limitations (4.6 for Zhejiang and 9.5 for Gansu) exceeded the mean (1.4 for Zhejiang and 3.4 for Gansu). Further, tests that examined whether the count variable was Poisson-distributed in each province suggested that it was not $\left(\chi^{2}=159.35, \mathrm{p}<0.001\right.$ and $\chi^{2}=208.96, \mathrm{p}<0.001$, for Zhejiang and Gansu, respectively) (Hoffman, 2004). Accordingly, we estimated negative binomial regression models using Stata 11's nbreg procedure.

Regression analysis assumes independence between the respondents. However, in the CHARLS data, the respondents who came from the same village could not be assumed to be independent of one another. One solution to this problem was the use of multilevel regression analysis. However, when using negative binomial regression, the use of multilevel regression has been shown in simulation studies to be problematic, yielding relatively biased and inefficient estimates. An acceptable alternative is to adjust the standard errors of the negative binominal regression coefficients to account for the non-independence of cases within a cluster (Andrews \& Caren, 2010). Therefore, this approach was used. Diagnostic checks revealed no problem with multicollinearity our outliers.

Initial analyses showed that villagers in Gansu were very different from those in Zhejiang with regard to their environmental, economic, and social conditions (Table 1). Therefore, 
regression results are presented separately for each province ( $\mathrm{N}=521$ in 30 villages for Zhejiang and $\mathrm{N}=571$ in 34 villages for Gansu) and comparisons made.

The results are reported in Table 2. An incidence rate ratio (IRR) greater than 1.00 indicates that higher values on the independent variable are associated with more IADL/functional limitations and an IRR below 1.00 indicates that higher values on the independent variable are associated with fewer IADL/functional limitations.

\section{Limitations of Data Analyses}

A major limitation of the data is that it is measured in only one point in time, that is, the study was not longitudinal. Any suggestions or references to causal effects can only be hypothetical — cross-sectional data do not allow for advanced tests of causality. A second limitation is the use of a village leader to obtain some of the village characteristics. Chinese village leaders were required to provide these types of information to government township offices. Unfortunately, the specific methods used by village leaders to collect these data were unclear. Therefore, it is unclear how accurate or unbiased these data are so these data must be considered cautiously.

\section{Results}

Table 1 presents descriptive statistics for all variables in the study by province. The respondents from the wealthier Zhejiang province are significantly healthier, needing help with only an average of 1.4 of the $12 \mathrm{IADL} /$ functional limitations measured compared to 3.4 among respondents from the much poorer Gansu province ( $\mathrm{p}<0.001$; all $\mathrm{p}$ values are two-tailed test). Further, $47 \%$ of the Zhejiang respondents needed no help at all with any of the 12 physical limitations compared to $19 \%$ in Gansu. 


\section{TABLE 1 ABOUT HERE}

An examination of the control variables shows that there were no differences by province when considering percent male, percent 60 years of age or older, and percent with rural Hukou status, but there was a significant difference regarding education with Gansu respondents more

likely to have had no formal education $((56 \%$ vs $44 \%)(\mathrm{p}<0.001)$. In contrast, the differences in the three environmental variables were all significant $(\mathrm{p}<0.001)$. Zhejiang villagers were much more likely to have sewage systems than those in Gansu (50\% vs $7 \%$ ) and much less likely to live in a village where one or more households were using coal (15\% vs $90 \%)$. When the village leaders were asked about the number of days per year that electricity was missed, those in Gansu were more likely to report that their villages had electricity 365 days per year as compared to those in Zhejiang (73\% vs $45 \%)$.

Examination of the economic variables again finds significant differences between Zhejiang and Gansu for all three variables ( $\mathrm{p}<0.001)$. The per capita net village income in 2007 was higher for Zhejiang respondents $(\mathrm{LN}=8.7 \mathrm{vs} \mathrm{LN}=7.1)$. Likewise, Zhejiang respondents had higher household expenditures per member in 2007 ( $\mathrm{LN}=8.6 \mathrm{vs} \mathrm{LN}=7.9)$ and paid a higher average unit price for electricity (.55 yuan/100 kilowatts vs .53).

Among the social variables, Zhejiang villages offered, on average, a higher number of programs for older adults than Gansu villages $(1.7$ vs 0.3$)(\mathrm{p}<0.001)$. A lower percentage of Zhejiang villagers lived near a health organization than did Gansu villagers $(69 \%$ vs $92 \%)(\mathrm{p}<$ 0.001). The NCMS variables show that a smaller percentage of villages in Zhejiang had been operating the program for only 3 years or less $(27 \%$ vs $88 \%)(\mathrm{p}<0.001)$. Further, Zhejiang villagers tended to pay more to participate in the program than Gansu villagers (31.6 yuan vs 
10.6 yuan) $(\mathrm{p}<0.001)$. No significant differences were found regarding the percentage of villagers who participated in the program and marital status.

An examination of the regression results shows a variety of significant effects on the number of IADL/functional limitations (Table $2 ; \mathrm{p}<0.001$ ). When considering the control variables, effects were consistent across province. Hukou status had no effect, males reported fewer limitations, those villagers who were 60 years and older reported more limitations and those with no formal education also reported more $(\mathrm{p}<0.001$ in Gansu and $\mathrm{p}<0.074$ in Zhejiang).

The effects of the environmental variables were less consistent across province. Having electricity 365 days a year may have been associated with fewer limitations in Gansu ( $p=0.055)$, but had no effect among Zhejiang respondents. Further, respondents in Zhejiang, who lived in a village where coal was used by at least one village household, experienced more physical limitations than Zhejiang villagers where no coal was used in households $(\mathrm{p}<0.001)$. On the other hand, Gansu respondents showed no relationship between coal use and limitations. When considering the existence of sewage systems, there was a clear negative effect on limitations in Gansu ( $\mathrm{p}<0.001)$, but no clear effect in Zhejiang $(\mathrm{p}<0.11)$.

\section{TABLE 2 ABOUT HERE}

The pattern of mixed effects by province continues to some extent when considering the economic variables. It appears that Gansu residents with higher expenditures per household member (a proxy for income) may have had fewer limitations $(\mathrm{p}<0.08)$, while the variable was 
not significant for Zhejiang. While more expensive electricity was associated with fewer limitations.

Five of the social variables, including all three of the NCMS variables, appeared to be associated with the number of ADL/functional limitations. In both Gansu and Zhejiang, respondents who were married reported fewer limitations $(\mathrm{p}<0.05)$. The effects of the other four variables were marginally significant and differed by province. The number of social programs provided by the village for older adults may have been associated with more IADL/functional limitations in Gansu $(\mathrm{p}<0.076)$ but not in Zhejiang. In Zhejiang villages, where the NCMS had been operating for only 3 or fewer years as compared to more than three years, physical limitations may have been higher $(\mathrm{p}<0.072)$. But, no association was found in Gansu. And, when considering the percentage of residents participating in the NCMS in Gansu, higher participation may have been associated with fewer limitations ( $\mathrm{p}<0.107)$, but no association was found between participation and limitations in Zhejiang. Finally, in Zhejiang, it appears that the number of reported limitations decreased by $1 \%$ for each associated yuan paid ( $\mathrm{p}$ $=0.052$ ) while in Gansu no association was found.

\section{Discussion}

The purpose of this study was to examine the three general propositions that there is a relationship between the health of the Chinese village older adults and their (1) environmental (Brunekreef \& Holgate, 2002; Shaw, et al., 2002; Pervin, Gerdtham, \& Lyttkens, 2008), (2) economic (Mazmanian \& Kraft, 2009; Li \& Chi, 2011; Zeng, et al., 2010), and (3) social characteristics (Gruenewald, et al., 2012; Pynnonen, et al., 2012). The CHARLS data support these propositions. Having a sewage system in Gansu villages reduced the number of reported 
physical limitations by $29 \%$ ( $\mathrm{p}<0.001)$. It is reasonable to expect that increased diseases may stem from a lack of a village sewage system and this in turn may result in poorer health and subsequently more physical limitations. Having electricity 365 days per year in Gansu may have reduced the number of limitations by $12 \%(\mathrm{p}<.067)$. A lack of dependable electricity can have a variety of negative effects as basic as the inability to routinely boil water and sterilize utensils. This, in turn, may negatively affect health and eventually the older villagers' physical limitations. And, in Zhejiang physical limitations were increased by $37 \%$ if the respondent lived in a village where one or more households used coal $(\mathrm{p}<0.001)$. Similar findings have been reported in previous studies examining the environment (e.g., Hunter, et al., 2011; Hart, 2006; Shaw, et al., 2002; Kruger, et al., 2007). The current findings suggest that rural Chinese village elderly are no different than elderly examined in earlier studies - their environment has clear links to their health.

Wealth of the village (measured as per capita net village income) was associated with fewer reported physical limitations in both Gansu and Zhejiang. The wealth of the household (measured as expenditure per household member) may have also been associated with fewer physical limitations in Gansu ( $\mathrm{p}$ < 0.08). These findings support earlier studies examining the effects of community and personal wealth on physical health (e.g., Mazmanian \& Kraft, 2009; Hart, 2006). On the other hand, it is not clear why there may have been an association between expenditures per household member and physical limitations in Gansu, but not in Zhejiang. Perhaps the measure used - expenditures per household member - did not completely capture the individual wealth of older villagers in Zhejiang. The third economic variable shows that higher electric costs in Zhejiang were associated with more physical limitations. One explanation is that a relatively high cost of electricity to a village was associated with wealthier villagers and 
wealthier villagers may have been more aware of their physical limitations. In sum, considering the three economic variables available, it is clear that wealth at the village level was associated with the physical limitations of older adults and that wealth at the individual level may have been associated with health in Gansu. This again supports previous research examining the impacts of community and individual wealth on health (Mazmanian \& Kraft, 2009; Chen \& Meltzer, 2008; Hart, 2006).

The social variables show that older villagers of both provinces, who were married, reported fewer physical limitations than those who were not married $(\mathrm{p}<0.01)$. A variety of explanations have been offered for this relationship (e.g., Mohnen, et al., 2011; Ellen, al., 2001; Pei \& Tang, 2010). Married people sometimes "trade" IADL and functional activities so that, for example, one person does all the cooking while the other manages the household budget. Consequently, a married person may be unaware of some limitations that she/he has because the spouse is performing those activities. This explanation is very similar to one given for the effect of sex on physical limitations $(\mathrm{Ji}, 2013)$. In this regard, the current analyses found that male respondents in Zhejiang and Gansu reported $42 \%$ and $26 \%$ fewer limitations, respectively, than female respondents $(\mathrm{p}<0.001)$. This result supports previous research and is often explained as a result of male respondents not recognizing that they have certain limitations. These go unrecognized because there is a female present who always performs these activities (e.g., doing household chores, shopping for groceries) that results in the male being unaware of his inability to do the activities.

Another social variable that may have had an effect on physical limitations in Gansu was the number of village programs for older adults $(\mathrm{p}=.076)$. The reporting of physical limitations increased 7 percent for each additional program in the village. One explanation is that the 
village programs alerted the older villagers to their physical limitations and those who were alerted were more likely to report them. However, it is unclear why there was no effect found in Zhejiang.

Macro-level social variables included effects of the NCMS. Zhejiang respondents, who lived in villages where the program was relatively new (had existed three years or fewer), may have experienced more physical limitations than those in villages where the program had operated longer $(\mathrm{p}>.072)$. This suggests that, where the NCMS program had more time to be used by Zhejiang residents, physical limitations were reduced, supporting the findings of Yi, et al. (2009) and Lei and Lin (2009). However, a similar relationship was not found in Gansu. Perhaps the high percentage of Gansu respondents living in villages where the program was relatively new (88\%) contributed to the lack of effect. A second NCMS variable that may have had an effect in Zhejiang was cost of the program to individual participants $(\mathrm{p}=0.052)$ - people who paid more tended to report fewer limitations. It is possible that those who paid more were generally wealthier villagers who received less or no government subsidies to participate while those who paid less to participate received subsidies. In sum, the social variables support previous studies by showing a relationship between social characteristics of elderly and their health (Berkman, et al., 2000; Veenstra, et al., 2005; Hart, 2006; Gruenewald, et al., 2012).

A comparison of respondents from the Zhejiang and Gansu provinces shows that sex, age and education had similar effects on health. The elders' physical limitations also appear to have been affected similarly regarding the wealth of the village $(\mathrm{p}<0.05)$, marital status $(\mathrm{p}<0.01)$, and possibly the existence of a sewage system ( $p<0.001$ for Gansu and $p=0.110$ for Zhejiang). On the other hand, several factors may have been important only in Gansu including the dependability of electricity $(\mathrm{p}=0.067)$, a person's individual wealth (measured as expenditures 
per household member) $(\mathrm{p}=0.080)$, number of programs for older adults $(\mathrm{p}=0.076)$, and possibly the percentage of villagers participating in the NCMS $(p=0.107)$. Four additional factors appear to have been important only in Zhejiang: 1) the use of coal by at least one household in the village ( $\mathrm{p}<0.001) ; 2)$ average unit price for electricity $(\mathrm{p}<0.05)$; 3$)$ the length of time the NCMS had been available in the village $(\mathrm{p}=0.072)$; and 4) villager's pay to participate in the NCMS ( $\mathrm{p}=0.052)$. It is not clear why some factors would be important in one province, but not in the other. However, given that Gansu and Zhejiang are very different economically and geographically, it is reasonable to suspect that these broader provincial differences played an important role.

Many social scientists from a variety of disciplines have directed their attention to community characteristics and how they affect the health and well-being of community residents (Mazmanian \& Kraft, 2009; Roosa, 2010; Wong, et al., 2006; Rogers, et al., 2008; Hallsmith, 2003). These scientists have concluded that it is environmental, economic, and social factors that combine to affect the health of a community or village. The current study allowed for an examination of each group of factors, while controlling for the others, and found support for these earlier conclusions.

\section{Implications for Social Policy}

There are several findings that standout with regard to social policy in China. The data show encouraging results regarding the New Cooperative Medical Scheme-the NCMS appeared to be associated with fewer physical limitations. This suggests that the NCMS may be helping to improve health among the older Chinese villagers. The findings also show a clear association between the lack of a village sewage system and increases in physical limitations in 
Gansu. This suggests that villages, particularly located in more rural and remote areas, such as many of those in Gansu, should be provided the means to obtain sewage systems. The data suggest that this would contribute toward better health of the older adults in these villages. Third, the use of coal in the home was found to be associated with more physical limitations for those living in the village. This suggests that identifying substitutes for the use of coal in the home could contribute to better health among the older village residents. Finally, the findings show an association between education and physical limitations - in both provinces, those older village adults with no formal education were much more likely to report physical limitations. This supports the conclusions of others that an investment in education is likely to result in better health (Orme \& Dooris, 2010; Beydoun \& Popkin, 2005). 


\section{References}

Andrews, K. T., \& Caren, N. (2010, December 9). Making the news: Movement organizations, media attention, and the public agenda. http://asr.sagepub.com/content/suppl/2010/12/9/75.6.841.DC1/ASR386689_online_suppl ement.pdf

Berkman, L. F., Glass, T., Brissette, I., \& Seeman, T. E. (2000). From social integration to health. Social Science and Medicine, 60, 2045-2057.

Bian, Y., \& Zhang, Z. (2002). Marketization and income distribution in urban China. The Future of Market Transition, 19, 377-415.

Brunekreef, B., \& Holgate, S. T. (2002). Air pollution and health. The Lancet, 360, 1233-1242.

Chen, R., Pan, G., Zhang, Y., Xu, Q., Zeng, G., Xu, X. et al. (2011). Ambient carbon monoxide and daily mortality in three Chinese cities. Science of the Total Environment, 409, $4923-$ 4928.

Chen, Z., \& Meltzer, D. (2008). Beefing up with the Chans. Social Science and Medicine, 66, 2206-2217.

Chow, N., \& Bai, X. (2011). Modernization and its impact on Chinese older people's perception of their own image and status. International Social Work, 54(6), 800-815.

Ellen, I. G., Mijanovich, T., \& Dillman, K.-N. (2001). Neighborhood effects on health. Journal of Urban Affairs, 23(3-4), 391-408.

Giles, J., \& Mu, R. (2007). Elderly parent health and the migration decisions of adult children. Demography, 44(2), 265-288. 
Gui, S. (2002, Winter). Attach importance to and do a good job of delivering community caregiving services to the doorsteps of the elderly. Chinese Sociology and Anthropology, 34(2), 89-93.

Hallsmith, G. (2003). The key to sustainable cities, meeting human needs, transforming community systems. Gabriola Island: New Society Pub.

Hara, K., Uwasu, M., Yabar, H., \& Zhang, H. (2009). Sustainability assessment with time-series scores. Sustainability Science, 4(1), 81-97.

Hart, M. (2006). Guide to sustainable community indicators. West Hartford, CT: Maureen Hart.

Hoffman, J. P. (2004). Generalized linear models. Boston: Pearson.

Hou, F., \& Myles, J. (2005). Neighbourhood inequality, neighbourhood affluence and population health. Social Science and Medicine, 60, 1557-1569.

Hunter, R. H., Sykes, K., Lowman, S. G., Duncan, R., Satariano, W. A., \& Belza, B. (2011). Environmental and policy change to support healthy aging. Journal of Aging and Social Policy, 23, 354-371.

Ji, J. (2013). Disparities of the Chinese elderly. Activities, Adaptation and Aging, 37, 19-46.

Kan, H., London, S. J., Chen, G., Zhang, Y., Song, G., Zhao, N. et al. (2008). Season, sex, age, and education as modifiers of the effects of outdoor air pollution on daily mortality in Shanghai, China. Environmental Health Perspectives, 116(9), 1183-1188.

Kruger, D. J., Reischi, T. M., \& Gee, G. C. (2007). Neighborhood social conditions mediate the association between physical deterioration and mental health. American Journal of Community Psychology, 40, 261-271.

Lei, X., \& Lin, W. (2009). The New Cooperative Medical Scheme in rural China. Health Economics, 18, S25-S46. 
Li, H., \& Zhu, Y. (2006). Income, income inequality, and health. ScienceDirect, 34, 668-693.

Li, X., \& Zhang, W. (December, 2012). The impacts of health insurance on health care utilization among the elderly in China. Presented at the International conference on aging and social security, Hong Kong, China: Gerontological Society of America.

Li, Y., \& Chi, I. (2011). Correlates of physician visits among older adults in China. Journal of Aging and Health, 23(6), 933-953.

Li, Y., \& Dorsten, L. (2011). Health of the elderly population in racially diverse cities and counties of Xinjang, China. Du Bois Review, 8(1), 53-61.

Martin, L. G., \& Preston, S. H. (1994). Demography of Aging. Washington, D.C.: National Academy Press.

Mazmanian, D. A., \& Kraft, M. E. (2009). Toward sustainable communities. Boston, MA: Massachusetts Institute of Technology.

Ministry of Health. (2003). Opinions on establishing the New Rural Medical System. China: Office of State Council.

Mohnen, S. M., Groenewegen, P. P., Volker, B., \& Flap, H. (2011). Neighborhood social capital and individual health. Social Science and Medicine, 72, 660-667.

Orme, J., \& Dooris, M. (2010). Integrating health and sustainability. Health Education Research, 25(3), 425-437.

Pei, X. (2008). Economically involved but socially excluded. Journal of Asian Women's Studies, 17, 31-47.

Pei, X. (2009). Society's support for the aged in China. Social Sciences in China, 30(1), 149-159.

Pei, X. (2011). Balancing efficiency and legitimacy. Social Policy and Administration, 45(6), $662-677$. 
Pei, X., \& Tang, Y. (2010). Old age protection in the context of rural development. IDS Bulletin, 41(4), 22-30.

Pei, X., \& Xu, Q. (2011). Old age security, inequality, and poverty. In S. Chen \& J. Powell (Eds.), Aging in perspective and the case of China (pp. 133-149). New York: Nova science publishers, Inc.

Pervin, T., Gerdtham, U.-G., \& Lyttkens, C. H. (2008). Societal costs of air pollution-related health hazards. Cost Effectiveness and Resource Allocation, 6, 1-22.

Rogers, P. P., Jalal, K. F., \& Boyd, J. A. (2008). An introduction to sustainable development. London: Earthscan.

Roosa, S. A. (2010). Sustainable development handbook. Lilburn: The Fairmont Press.

Ross, C. E., \& Mirowsky, J. (2008). Neighborhood socioeconomic status and health. City and Community, 7(2), 163-179.

Shaw, D., Brown, P. J., Massey, D. W., \& Wang, X. (2002). Urban growth and development in Shanghai. In S. Romaya \& C. Rakodi (Eds.), Building sustainable urban settlements: Approaches and case studies in the developing world (pp. 32-47). London: ITDG Publishing.

State Council. (2002). Decisions of the state council on strengthening rural healthcare. China: Office of State Council.

Strauss, J. P., Lei, X., Park, A., Shen, Y, Smith, J. P., Yang, Z., Zhao, Y. (2011). Health outcomes and socio-economic status among the elderly in China: Evidence from the CHARLS pilot. Population Ageing, 3, 111-142.

Tilt, B. (2010). The Struggle for sustainability in rural China. New York: Columbia University Press. 
Veenstra, G., Luginaah, I., Wakefield, S., Birch, S., Eyles, J., \& Elliott, S. (2005). Who you know, where you live. Social Science and Medicine, 60, 2799-2818.

Wang, X., Shang, X., \& Xu, L. (2011). Subjective well-being poverty of the elderly population in China. Social Policy and Administration, 45(6), 714-731.

Weichenthal, S., Kulka, R., Dubeau, A., Martin, C., Wang, D., \& Dales, R. (2011). Trafficrelated air pollution and acute changes in heart rate variability and respiratory function in urban cyclists. Environmental Health Perspectives, 119(10), 1373-1378.

Wen, M., \& Gu, D. (2011). Air pollution shortens life expectancy and health expectancy for older adults. Journals of Gerontology: Series A: Biological Sciences and Medical Sciences, 67(11), 1219-1229.

Wing, Chan, K., \& Buckingham, W. (2008). Is China abolishing the hukou system? The China Quarterly, 195, 582-606. DOI: http://dx.doi.org/10.1017/S0305741008000787

Wong, C. M., Yang, L., Thach, T. Q., Chau, P. Y., Chan, K. P., Thomas, G. N. et al. (2009). Modification by influenza on health effects of air pollution in Hong Kong. Environmental Health Perspectives, 117(2), 248-253.

Wong, T.-C., Shaw, B. J., \& Goh, K. C. (2006). Challenging sustainability: Urban development and change in Southeast Asia. Singapore: Marshall Cavendish Academic.

World Commission on Environmental Development. (1987). Our Common Future. Melbourne: Oxford University Press Australia.

Xu, Q., Gao, J., \& Yan, M. C. (2005). Community centers in urban China. Journal of Community Practice, 13(3), 73-90.

Xun, W. (2002, Winter). Reform and improve the medical care system to enhance the quality of life among the elderly. Chinese Sociology and Anthropology, 34(2), 85-88. 
Yao, Y. (2002, Fall). Weakening family support for the elderly in China. Chinese Sociology and Anthropology, 34(1), 26-34.

Ye, 1. (2011). Demographic transition, developmentalism, and social security in China. Social Policy and Administration, 45(6), 678-693.

Yi, H., Zhang, L., Singer, K., Rozelle, S., \& Atlas, S. (2009). Health insurance and catastrophic illness. Health Economics, 18, S119-S127.

Yip, W., \& Hsiao, W. C. (2009). Non-evidence-based policy. Social Science and Medicine, 68, 201-209.

Yip, W., Subramanian, S., Mitchell, A. D., Lee, D. T., Wang, J., \& Kawachi, I. (2007). Does social capital enhance health and well-being? Social Science \& Medicine, 64, 35-49.

Zavoretti, R. (2006). Family-based care for China's ageing population. Asia Europe Journal, $4(2), 211-228$.

Zeng, Y., Gu, D., Purser, J., Hoenig, H., \& Christakis, N. (2010). Associations of environmental factors with elderly health and mortality in China. American Journal of Public Health, 100(2), 298-305.

Zhang, J., Mauzerall, D. L., Zhu, T., Liang, S., Ezzati, M., \& Remais, J. V. (2010). Environmental health in China. The Lancet, 375, 1110-1119.

Zhao, Y., Strauss, J. P., Sun, Y. (2009). Chinese Health and Retirement Longitudinal StudyPilot. Beijing: National School of Development, Peking University.

Zimmer, Z., Kaneda, T., \& Spess, L. (2007). An examination of urban versus rural mortality in China using community and individual data. The Journal of Gerontology, 62B(5), S349S356. 
Table 1. Distribution of Dependent and Independent Variables by Province $(N=1,267)$

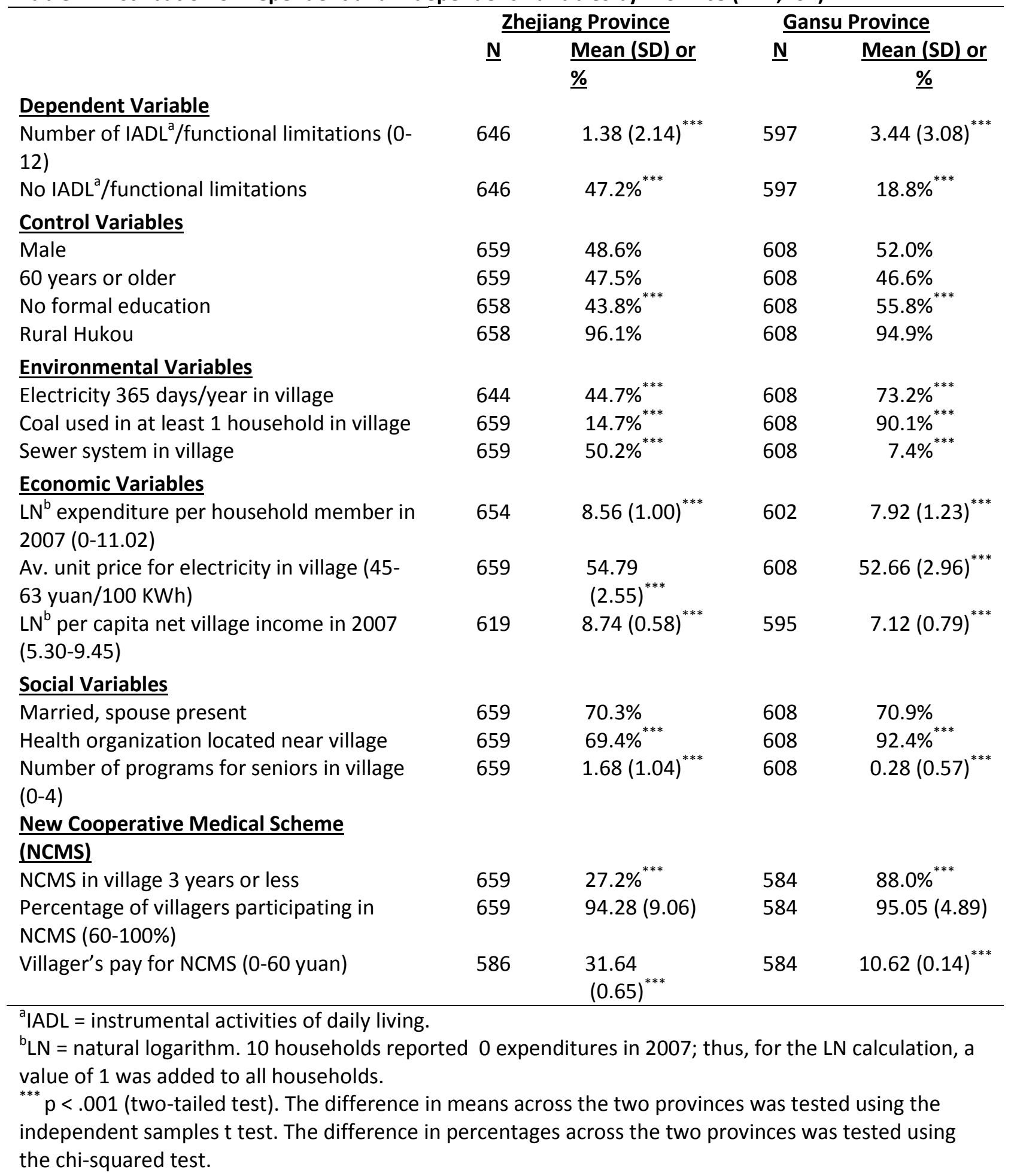


Table 2. Results of Negative Binomial Regressions of Number of IADL ${ }^{\mathrm{a}} /$ Functional Limitations on Selected Variables by Province $(N=1,092)$

\begin{tabular}{|c|c|c|c|c|c|c|}
\hline \multirow[b]{2}{*}{ Control Variables } & \multicolumn{2}{|c|}{ Zhejiang Province } & \multicolumn{3}{|c|}{ Gansu Province } & \multirow[b]{2}{*}{$\frac{p>}{|z|^{d}}$} \\
\hline & $\underline{B(S E)^{b}}$ & $\underline{\mathbf{I R R}^{\mathrm{c}}}$ & $\frac{p>}{|z|^{d}}$ & $\underline{B(S E)^{b}}$ & $\underline{\mathbf{I R R}^{\mathbf{c}}}$ & \\
\hline Male & $\begin{array}{l}-0.548 \\
(0.145)\end{array}$ & 0.578 & $<0.001$ & $\begin{array}{l}-0.303 \\
(0.090)\end{array}$ & 0.739 & 0.001 \\
\hline 60 years or older & $0.987(0.124)$ & 2.683 & $<0.001$ & $0.488(0.085)$ & 1.629 & $<0.001$ \\
\hline No formal education & $0.322(0.180)$ & 1.379 & 0.074 & $0.282(0.082)$ & 1.326 & 0.001 \\
\hline Rural Hukou & $0.219(0.249)$ & 1.245 & 0.377 & $0.094(0.205)$ & 1.098 & 0.648 \\
\hline \multicolumn{7}{|l|}{ Environmental Variables } \\
\hline $\begin{array}{l}\text { Electricity } 365 \text { days/year } \\
\text { in village }\end{array}$ & $\begin{array}{l}-0.024 \\
(0.143)\end{array}$ & 0.976 & 0.864 & $\begin{array}{l}-0.131 \\
(0.072)\end{array}$ & 0.877 & 0.067 \\
\hline $\begin{array}{l}\text { Coal used in at least } 1 \\
\text { household in village }\end{array}$ & $0.317(0.089)$ & 1.373 & $<0.001$ & $0.027(0.078)$ & 1.028 & 0.728 \\
\hline Sewer system in village & $0.165(0.104)$ & 1.180 & 0.110 & $\begin{array}{l}-0.337 \\
(0.072)\end{array}$ & 0.714 & $<0.001$ \\
\hline \multicolumn{7}{|l|}{ Economic Variables } \\
\hline $\begin{array}{l}\mathrm{LN}^{\mathrm{e}} \text { expenditure per } \\
\text { household member in } \\
2007\end{array}$ & $\begin{array}{l}-0.032 \\
(0.055)\end{array}$ & 0.969 & 0.562 & $\begin{array}{l}-0.039 \\
(0.022)\end{array}$ & 0.962 & 0.080 \\
\hline $\begin{array}{l}\text { Average unit price for } \\
\text { electricity in village }\end{array}$ & $.043(.020)$ & 1.044 & 0.032 & $-0.013(.015)$ & 0.987 & 0.374 \\
\hline $\begin{array}{l}\text { LN per capita net village } \\
\text { income in } 2007\end{array}$ & $\begin{array}{l}-0.221 \\
(0.109)\end{array}$ & 0.802 & 0.043 & $\begin{array}{l}-0.111 \\
(0.043)\end{array}$ & 0.895 & 0.010 \\
\hline \multicolumn{7}{|l|}{ Social Variables } \\
\hline Married, spouse present & $\begin{array}{l}-0.342 \\
(0.135)\end{array}$ & 0.710 & 0.011 & $\begin{array}{l}-0.276 \\
(0.094)\end{array}$ & 0.759 & 0.003 \\
\hline $\begin{array}{l}\text { Health organization } \\
\text { located near village }\end{array}$ & $0.106(0.082)$ & 1.112 & 0.197 & $0.083(0.073)$ & 1.087 & 0.252 \\
\hline $\begin{array}{l}\text { Number of programs for } \\
\text { seniors in village }\end{array}$ & $\begin{array}{l}-0.001 \\
(0.036)\end{array}$ & 0.999 & 0.977 & $0.071(0.040)$ & 1.073 & 0.076 \\
\hline $\begin{array}{l}\text { New Cooperative Medical } \\
\text { Scheme (NCMS) }\end{array}$ & & & & & & \\
\hline $\begin{array}{l}\text { NCMS in village } 3 \text { years or } \\
\text { less }\end{array}$ & $0.255(0.142)$ & 1.290 & 0.072 & $\begin{array}{l}-0.005 \\
(0.090)\end{array}$ & 0.995 & 0.953 \\
\hline $\begin{array}{l}\text { Percentage of villagers } \\
\text { participating in NCMS }\end{array}$ & $0.004(0.005)$ & 1.004 & 0.407 & $\begin{array}{l}-0.013 \\
(0.008)\end{array}$ & 0.988 & 0.107 \\
\hline Villager's pay for NCMS & $\begin{array}{l}-0.006 \\
(0.003)\end{array}$ & 0.994 & 0.052 & $0.010(0.014)$ & 1.010 & 0.448 \\
\hline Constant & $\begin{array}{l}-0.845 \\
(1.147)\end{array}$ & & 0.461 & $3.882(0.854)$ & & $<0.001$ \\
\hline Model Wald $X^{2}$ & 897.60 & & & $1,294.80$ & & \\
\hline Model degrees of freedom & 16 & & & 16 & & \\
\hline$p$-value & $<0.001$ & & & $<0.001$ & & \\
\hline $\mathrm{N}$ & 521 & & & 571 & & \\
\hline
\end{tabular}


${ }^{\mathrm{a}} \mathrm{IADL}=$ instrumental activities of daily living.

${ }^{b} B=$ unstandardized negative binomial regression coefficient estimate; $S E=S t a n d a r d$ error, adjusted for clustering of elders at the village-level (30 villages in Zhejiang and 34 in Gansu).

${ }^{\mathrm{C}} \mathrm{IRR}=$ Incidence rate ratio $\left(\exp ^{\mathrm{B}}\right)$.

${ }^{\mathrm{d}}$ Two-tailed $\mathrm{p}$-values are reported.

${ }^{\mathrm{e}}$ Natural logarithm. 